\title{
Teaching medical ethics as a practical subject: observations from experience
}

\author{
Alan G Johnson Professor of Surgery, University of Sheffield
}

\section{Editor's note}

The author, head of a teaching hospital surgical unit, argues that the medical curriculum must ensure that all students are exposed to a minimum of ethical discussion and decision-making. In describing his own approach he emphasises the need to show students that it is 'an intensely practical subject'. Moreover, he reminds them that moral dilemmas in medicine - perhaps a better term than medical ethics - are unavoidable in clinical practice. Professor fohnson emphasises the need for small group teaching and discussion of real cases, preferably chosen and 'worked up' by individual students. He suggests that ethical issues could profitably be introduced into written, oral and clinical examinations.

Over the last I5 years, there has been an increasing interest in all aspects of medical ethics both by the media and by the medical profession. The success of this Journal bears witness to this phenomenon but a recent editorial (I) rightly questioned whether the interest is reflected in the teaching of students in our medical schools, despite a recommendation by the General Medical Council in 1967. It seems an appropriate time to give some answers, from I2 years' experience, to why, how and when ethics should be imparted to medical students.

\section{Do ethics have to be taught?}

There is a commonly held belief, particularly amongst older consultants, that ethics are assimilated from the example of senior staff on ward rounds and that there is no need to spell out the issues in detail. Although example is a strong influence and it is important to 'practise what you preach', ethical issues are now too complicated to be managed in this way. Students must be allowed to question decisions, teachers must try to justify them. The all too frequent experience of students standing silently and helplessly on the sidelines while the consultant speaks to the patient in deceptive euphemisms, is not a sound way of teaching medical ethics.

\section{Key words}

Teaching medical ethics; mechanisms of decision-making; the basis of ethics; aims of teaching; curriculum.

\section{Who should teach ethics?}

Informed opinion from many different disciplines, besides medicine, can make a useful contribution to the ethical debate: theologians, lawyers and MPs and, not least, the patient, all have a valid point of view. There is a definite place for a university department such as the Centre for Law, Medicine and Ethics at King's College, London whose members can write and analyse, inform and challenge. But ultimately the $a p$ plied teaching must be done by those in the forefront of research and clinical medicine who are actually making the decisions. It is easy for the medical profession to shirk its responsibility either by saying 'the State must decide what it wants us to do' or by appointing a solitary, departmentless, 'professional ethicist' to its staff. There is no need for the doctor to feel threatened by advice and analysis from non-medicals any more than there is a need for him to abandon his decisionmaking to them. Perhaps this threat comes from the doctors' unfamiliarity with the subject and its jargon. It only needs a few medical teachers in each medical school to get together, with the support of the Dean and advice from non-medical experts, to start the whole process.

\section{Who should be taught?}

Much of the teaching over the last I 5 years has been on a voluntary basis, and often, organised outside the medical school by such organisations as the London Medical Group (and its equivalent in other cities), the Society for Medicine and Religion and the Christian Medical Fellowship. These meetings often attract a good attendance - but of students who are already interested and concerned about ethical problems. Television has done much in the last five years to bring the more dramatic issues to the attention of medical students and lay public alike. Student interest is also aroused by elective periods and visits to special units, such as hospices, during their training. But all this leaves a significant proportion of students qualifying without having to think constructively about the many ethical issues they will shortly face. The students who are not apparently interested in medical ethics are the very ones who should be taught, because medical ethics is no optional extra but is inextricably entwined 
with everyday clinical decision-making. I am forced to the conclusion that the curriculum must ensure that all students are exposed to a minimum of ethical discussion and decision-making. Those who develop a special interest can follow this up through the many voluntary channels. Compulsory lectures in the present climate, might not be the right method, but other alternatives are discussed below.

\section{What are the aims of teaching?}

It is very important to have clearly defined aims. I will enunciate them, not in order of importance, but in the order in which they are usually discussed.

\section{I) THE NATURE OF MEDICAL ETHICS}

So many people still imagine the subject is suitable only for the absent-minded, much-caricatured university Don! Students must be shown that it is an intensely practical subject. The very name is unhelpful perhaps 'moral dilemmas in medicine' (2) is a more meaningful alternative. Students must also be shown that if they intend to practise clinical medicine they cannot escape from difficult decisions, many of which will become more difficult as time goes on.

\section{2) AWARENESS OF THE PROBLEMS}

This is easy with the well-publicised subjects such as abortion, euthanasia and transplantation. But, as Ian Kennedy (3) has so rightly pointed out, the stuff of ethics is illustrated just as well by the small decisions of everyday clinical medicine as by the headlinecatching crisis points. He stresses the importance of such principles as truth-telling and promise-keeping and respecting the dignity of the individual. These may be violated a hundred times in the life of the average student's clinical experience.

\section{3) THE MECHANISMS OF DECISION-MAKING}

In order to make it clear how decisions are arrived at it is necessary to demonstrate how to analyse a problem:for example, how to distinguish between moral and technical questions. We must show that guidelines can be given and that logical decisions can be made, once the issues are clearly defined. It is not necessary or responsible to walk into a situation and then hope that commonsense or inspired guesswork will produce the right decision. 'Situation ethics', Kennedy points out (3), is no ethics at all. Students must be shown not only how these analyses have been made and resolved in the past (for example, in reference to brain death and transplantation) but must also be given a framework (4) which will enable them to make right decisions in the future. As in the teaching of clinical medicine, we must prepare the new house officer to face situations, the exact copy of which he has not seen before.
4) INFORMATION ON EXISTING ETHICAL GUIDES AND $\stackrel{\mathbb{Q}}{2}$ SAFEGUARDS

Many students are ignorant of the Hippocratic Oathe even though the public still believes they all swear it on: qualification. There are many other modern declara $\stackrel{5}{?}$ tions covering such subjects as the definition of death? transplantation (Declaration of the World Medica $\bar{P}$. Association, Sydney, 1968) and research (Declarationf of the World Medical Association, Helsinki, I 964$) \stackrel{\mathbb{\complement}}{\varrho}$ Most students have only a very vague idea of the work in ing of hospital or district ethical committees or the Home Office licensing system for animal experiments? Many have never actually read the 1967 Abortion Act $\vec{\omega}$ or seen and analysed the voluntary euthanasia billso rejected by the House of Lords in recent years. It was. interesting to note how many doctors, as well as students, were vague about the actual issues involved in the recent 'Mongol Baby' trial at Leicester. Theseir are all concrete proposals or events which can be an-은 alysed and discussed with profit.

The Medical School library has an important part to play. It should be the Librarians' responsibility, ad $\frac{0}{\circ}$ vised by the teaching staff, to have a balanced stock of 5 books with several copies of those which students fre-e quently borrow.

\section{5) THE UNDERLYING BASIS OF ETHICS}

This, in some ways, is the most important part because⿳亠丷⿵冂丶 ethics must have its basis in a conviction of what is right and wrong, a system of values, and in views of respon $\vec{r}$ sibility. To analyse a problem is not to solve it and after the analysis, if we are to speak of right and wrong, we must know by what standard the right and wrong is being judged. It is therefore an important part of teach ing to question the basis of accepted practice and to ask why doctors do what they do. In fact we might questionowhether medical ethics exists at all, or whether we. should merely speak of personal ethics applied to medicine. Although it would be comforting and easy to teach an agreed set of principles which comprise theo body of 'medical ethics', this is no longer possible. We are a pluralistic country and a pluralistic profession ando one certainly does not reach a satisfactory medical ethic by finding the highest common factor of all religions and world philosophies.

These aspects of medical ethics are the most disturbing for students but should not be glossed over. We may suggest that truth is a basic tenet of medical ethics but there are many people in our society and some in our profession for whom truth is an expendable cons venience. We may suggest that doctors should put a very high value on human life yet there are those whose philosophy clearly judges human value solely by its usefulness to the State. Do we ask people who join the profession to disown their personal beliefs for the sake of common agreement? Do we eliminate, by nonselection for posts, those with a certain system of valo ues, as has largely happened in gynaecology? Or do we 
accept the pluralism of the profession? These are important questions for the future and questions which students are increasingly aware of and keen to discuss.

\section{Methods}

It has already been hinted that formal lectures alone are not the best way to teach medical ethics, but what are the alternatives? At what stage in the curriculum should such teaching come and in what context?

\section{TEACHING FORMAT}

There is little doubt that in this, of all subjects, smallgroup teaching is necessary to allow everybody to join in discussion. There is still a place for formal lectures by one or more speakers, and it is often helpful to hear an eminent speaker explain the logic of his position and then answer questions, but there can be no real discussion in a lecture theatre. Lectures can also give a basis of information for use in small-group discussion. The advantage of a small group which is a natural clinical unit is that principles can be applied to patients or problems which are familiar to all. At the end of the day we want doctors to be able to make ethical decisions not just join in endless debates and questions. The most useful part of our own seminars is that the students themselves choose and prepare a topic beforehand: this means they have to think and read about it and sort out their own ideas.

\section{TIMING IN CURRICULUM}

Any planned teaching of ethics must not be so early in the course that the students are unaware of the clinical problems, nor so late that it is just before final examinations when the students' minds are preoccupied. The timing will therefore depend on the structure of the course and how soon clinical medicine is introduced. It seems wise to have a lecture or two in the introductory clinical course to bring ethical problems to the students' attention and give a correct perspective. Occasional seminars can then be introduced during the main clinical appointments and, of course, in any specialist course such as gynaecology and obstetrics. The beginning of house jobs is also an important time and ethical issues can be part of an Induction Day, if such exists.

\section{AN EXAMINATION}

It is often said that students will not take any subject seriously unless there is an examination at the end! I do not recommend a formal examination in ethics although an informal questionnaire may help to evaluate a course. If students are preparing their own topics then they have to be involved, not passive listeners. However, there is no reason at all why ethical implica- 'tions should not be added as a rider at the end of an essay question or why issues such as what to tell the patient should not be discussed in clinical examinations and vivas. Perhaps even a whole question could be based on a case history of mainly ethical content. This has the added benefit of stressing that ethics is not a separate subject but an integral part of clinical decisions.

\section{PROBLEMS OF ORGANISATION}

One of the problems of modern clinical medical curricula is that students rotate from department to department so frequently that they hardly have time to get to know their teachers and to form the sort of understanding that is necessary for frank discussions. It also becomes difficult to ensure that all students will pass through a particular unit. When students are rotating through several teaching hospitals and out to district general hospitals, it is essential for those concerned with ensuring some ethical teaching for all, to select a number of clinical appointments through which at some time all students will pass. Seminar teaching can then be concentrated in these: it does not matter whether they are surgical or medical provided the teachers are enthusiastic and informed.

\section{Conclusion}

I have no doubt that we have a responsibility to 'impart' (5) ethics to medical students - a word which implies teaching, discussion and example. Moral problems will not go away just because we ignore them indeed they are likely to become more complicated in the future if the last 20 years are any guide. To allow our students to qualify without any framework by which to make ethical decisions is just as bad as allowing them to qualify without knowing how to diagnose a perforated ulcer or how to choose an appropriate hypotensive drug. Moreover, many students, at the beginning, are more idealistic about patient care than their teachers and we have a duty to show them how their ideals can be retained and applied to difficult moral decisions, rather than abandoned during medical training.

\section{References}

(I) Anonymous. Medical ethics and medical education [Editorial]. Foumal of medical ethics 1981; 7: 171-172.

(2) Campbell A V. Moral dilemma in medicine. 2nd Ed. Edinburgh: Churchill Livingstone, 1975.

(3) Kennedy I. Rethinking medical ethics. Foumal of the Royal College of Surgeons of Edinburgh $1982 ; 27$ : $1-8$.

(4) Bliss B P and Johnson A G: Aims and motives in clinical medicine. London: Pitman Medical, 1975.

(5) Crouch M. Imparting ethics to medical students. London: Christian Medical Fellowship Publications, 1977. 